\title{
Ultrastructural and Molecular Phylogenetic Identification of the Diplomonad Flagellate Spironucleus salmonis Infecting Hatchery-reared Salmonid Fishes in Hokkaido
}

\author{
Shinya Mizuno ${ }^{1 *}$, Shigehiko Urawa ${ }^{2}$, Yoshitomo Katsumata ${ }^{1}$, \\ Takumi Morishita ${ }^{3}$ and Masatoshi Ban ${ }^{2}$ \\ ${ }^{1}$ Salmon and Freshwater Fisheries Research Institute, Hokkaido Research Organization, \\ Hokkaido 061-1433, Japan \\ ${ }^{2}$ Hokkaido National Fisheries Research Institute, \\ Japan Fisheries Research and Education Agency, \\ Hokkaido 062-0922, Japan \\ ${ }^{3}$ Chitose Field Station, Hokkaido National Fisheries Research Institute, \\ Japan Fisheries Research and Education Agency, \\ Hokkaido 066-0068, Japan
}

(Received September 19, 2019)

\begin{abstract}
Systemic infections caused by diplomonad flagellates belonging to the genus Spironucleus commonly result in heavy mortalities in salmonids. Diplomonad flagellates were found in the intestinal lumen of hatchery-reared juvenile chum Oncorhynchus keta and masu salmon O. masou in Hokkaido. We performed ultrastructural observation and molecular phylogenetic analysis using the small subunit ribosomal RNA gene (SSUrDNA) of the flagellates to clarify their taxonomy. The flagellates showed elongated and tapered nuclei, and sub-apical location of the kinetosomes relative to the nuclei: which are the distinguishing characters of the genus Spironucleus among three genera of parasitic diplomonads. In addition, the flagellates had electron dense plaques at their posterior end, a posterior sac of dense free ribosomes, an electron dense body, and bowl-shaped membranous structures, identifying them as S. salmonis among four Spironucleus species that affect fish. The ultrastructure of the flagellates showed no variations between the two host species of salmon. All the isolated flagellate SSUrDNAs had the same 1,031 bp sequence, and no difference in the sequence. The SSUrDNA showed the highest homology (99\%) with S. salmonis among 11 diplomonad flagellates. Thus, this study successfully used ultrastructure diagnosis and molecular phylogenetic analysis to confirm S. salmonis as the diplomonad flagellate that has infected hatchery-reared chum and masu salmon in Hokkaido.
\end{abstract}

Key words: Spironucleus salmonis, diplomonad flagellate, chum salmon, masu salmon, molecular phylogeny, electron microscopy, SSUrDNA, ultrastructure

Parasitic diplomonad flagellates of genus Spironucleus are found worldwide in the intestinal-tract lumen of freshwater and marine fishes, both in aquaculture and in the wild (Poynton and Morrison, 1990; O'Breien et al., 1993; Sterud, 1998; Sterud et al.,1998; Tojo and Santamaria, 1998; Paull and Matthews, 2001; Sterud et al., 2003; Guo and Woo, 2004; Jorgensen and Sterud, 2004, 2006). Systemic infection with Spironucleus parasites, or spironucleosis, commonly results in heavy mortality in juveniles of farmed salmon (Mo et al., 1990; Kent et al., 1992; Poppe et al., 1992;

\footnotetext{
* Corresponding author

E-mail: mizuno-shinya@hro.or.jp
}

Poppe and Mo, 1993; Sterud et al.,1998). The pathology of spironucleosis includes epithelial necrosis of the intestinal lumen, internal hemorrhaging, splenomegaly, and granulomatous lesions in the liver and spleen in the host. In Japan, infection with Spironucleus salmonis (formerly Hexamita salmonis) was first detected in juvenile rainbow trout Oncorhynchus mykiss farmed in Nagano, Shizuoka, Tochigi and Yamanashi prefectures, with host mortalities of $10 \%-30 \%$ in farm ponds (Sano and Ushiyama, 1970). The parasite was also found in the intestinal lumen of juvenile chum salmon $O$. keta, pink salmon $O$. gorbuscha, and masu salmon $O$. masou reared in hatcheries in Hokkaido, northern Japan, for stock enhancement (Awakura and Matsumoto, 1970; 
Urawa and Awakura, 1994; Urawa 2011; Urawa et al., 2018*). An infection experiment with S. salmonis caused a cumulative mortality of approximately $20 \%$ in juvenile masu salmon, and was accompanied by a low condition factor of the fish (Urawa, 2011; Urawa et al., 2018*).

To date, all references reported in Japan have identified the diplomonad flagellates infecting salmonids as S. salmonis, through light microscopy and/or scanning electron microscopy (SEM). However, for morphological identification to the genus and species level, it is essential to investigate these diplomonads using transmission electron microscopy (TEM) (Brugerolle, 1975; Poynton and Sterud, 2002; Urawa, 2011; Williams et al., 2011). The three diplomonad genera known to affect fish-Spironucleus, Hexamita and Octomitusare distinguished by presence of a cytoskeleton and the locations of organelles. Four parasitic Spironucleus spp., namely S. salmonis, S. salmonicida (formerly S. barkhanus), S. torosa and $S$. vortens, are classified based on characteristics of the microtubular and fibrillar elements and the presence of distinctive organelles. Nonetheless, even expert morphological investigations through SEM and TEM may fail to accurately identify species of Spironucleus parasites (Jorgensen and Sterud, 2006). Molecular phylogenetic analysis based on sequencing of the small subunit ribosomal RNA gene (SSUrDNA) has proven useful in determining the taxonomy and phylogeny of Spironucleus parasites (Jorgensen and Sterud, 2007). Partial SSUrDNA nucleotide sequences of S. salmonis, S. salmonicida (formerly S. barkhanus), S. barkhanus, S. torosa and S. vortens have been registered at Genbank (National Center for Biotechnology Information, Rockville, MD, USA) and are utilized for the taxonomy of Spironucleus parasites.

The present study performed SEM, TEM, and molecular phylogenetic analysis of SSUrDNA from flagellates infecting hatchery-reared chum and masu salmon in Hokkaido, to clarify the taxonomy of these diplomonads.

\section{Materials and Methods}

\section{Sampling}

Underyearling chum salmon (average body weight $0.547 \mathrm{~g}$ ) and yearling masu salmon (average body weight $16.7 \mathrm{~g}$ ) were individually collected from ponds at the Chitose Field Station of the Hokkaido National Fisheries Research Institute, central Hokkaido, Japan,

\footnotetext{
* Urawa, S., S. Mizuno and M. Ban (2018): Impact of Spironucleus salmonis on the growth and mortality of juvenile masu salmon Oncorhynchus masou. Abstracts of 8th International Symposium on Aquatic Animal Health, September 2-6, 2018, Charlottetown, PEI, Canada. Available at: https:// isaah2018.com/
}

on 20 April 2018. All fish were dissected using sterilized forceps and scissors. The entire intestine excluding the pyloric caeca and the vent was sampled from each fish. A center part of each intestine sample was cut out to confirm infection with flagellar swimming trophozoites of a diplomonad flagellate, through microscopy of smears at $\times 200$ magnification. The remainder of the intestine samples from chum salmon $(n=5)$ and masu salmon ( $n=5)$, which were found to be heavily infected with diplomonad flagellates, were cut into round slices (diameter $1 \mathrm{~mm}$ ), to be used for SEM, TEM, and molecular phylogenetic analysis of the parasite.

\section{Electron microscopic observation}

Half of the sliced intestine sample from each fish was fixed with $2.0 \%$ glutaraldehyde and $2.0 \%$ paraformaldehyde in $0.1 \mathrm{M}$ phosphate buffer (PB) $(\mathrm{pH} 7.2)$, at $4^{\circ} \mathrm{C}$, overnight. After this fixation, the samples were washed three times with $0.1 \mathrm{M}$ PB for 30 min each, and then post-fixed with $2.0 \%$ osmium tetroxide in $0.1 \mathrm{M} \mathrm{PB}$, at $4{ }^{\circ} \mathrm{C}$, for $3 \mathrm{~h}$. The post-fixed samples were dehydrated in a graded series of ethanol (each of 50, 70, 90 and $100 \%$ ) for $30 \mathrm{~min}$ at room temperature. Some dehydrated samples were immersed in $5 \%$ ionic liquid HILEM (IL-1000; Hitachi High-Technologies, Tokyo, Japan) to establish electrical conductivity, which allowed omission of critical point drying and metal-coating in preparing the samples for SEM. SEM was performed with a Miniscope TM3030 Plus (Hitachi High-Technologies). Other dehydrated samples were infiltrated with propylene oxide, two times, for $30 \mathrm{~min}$, and then embedded in resin (Quetol-812; Nisshin EM, Tokyo, Japan). Next, 70-nm sections of embedded samples were prepared using the diamond knife of an ultramicrotome (Ultracut UCT; Leica, Vienna, Austria), followed by staining with $2 \%$ uranyl acetate for $15 \mathrm{~min}$, and with Lead stain solution (Sigma-Aldrich, Tokyo, Japan) for $3 \mathrm{~min}$. The TEM was observed with the JEM-1400Plus (JEOL, Tokyo, Japan).

\section{SSUrDNA cloning and sequencing}

Total DNA and partial RNA were extracted from the other half of the intestine samples for each fish, using a nucleic acid extraction kit (SepaGene; Sekisui Medical, Tokyo, Japan). In brief, the intestine samples were homogenized in $100 \mu \mathrm{L}$ of Tris-EDTA buffer (10 mM of Tris- $\mathrm{HCl}$ and $1 \mathrm{~mm}$ of EDTA; $\mathrm{pH} 8.0)$. Nucleic acids were extracted from the homogenized sample using the phenol-chloroform method, and resuspended in $20 \mu \mathrm{L}$ of Tris-EDTA buffer. Polymerase chain reaction (PCR) was performed to amplify the PCR products originating from the partial SSUrDNA using a primer set common to diplomonad flagellates of the genera Spironucleus, Hexamita and Octomitus, which are known parasites of fish. The nucleotide sequences of the primers were 5'-GGAAGGCAGCAGGCGCGGA-3' for the forward 
primer, and 5'-AGCGACGGGCGGTGTGTAC-3' for the reverse primer. A $50-\mu \mathrm{L}$ aliquot of the PCR mixture was composed of $2 \mu \mathrm{L}$ of nucleic acid template, $25 \mu \mathrm{L}$ of 2xPCR mixture (AmpliTaq Gold 360 Master Mix; Applied Biosystems, Foster City, CA, USA), $0.5 \mu \mathrm{L}$ of $50 \mu \mathrm{m}$ forward primer, $0.5 \mu \mathrm{L}$ of $50 \mu \mathrm{m}$ reverse primer, and $22 \mu \mathrm{L}$ of distilled water. The thermal cycles of PCR were one cycle of enzyme activation for $10 \mathrm{~min}$ at $95^{\circ} \mathrm{C}, 40$ cycles of denaturation for $30 \mathrm{~s}$ at $95^{\circ} \mathrm{C}$, primer annealing for 30 s at $60^{\circ} \mathrm{C}$ and extension for $2 \mathrm{~min}$ at $72^{\circ} \mathrm{C}$, and one cycle of complete extension for $7 \mathrm{~min}$ at $72^{\circ} \mathrm{C}$. The amplified PCR products were ligated into the PCR2.1 plasmid vectors and isolated using a TA Cloning Kit (Invitrogen, Carlsbad, CA, USA). At least 100 PCR products for each the chum salmon and masu salmon were sequenced in both directions using an automated $\mathrm{ABI}$ PRISM 377 DNA Sequencer (Applied Biosystems), dye terminators, and $\mathrm{M} 13$ forward and $\mathrm{M} 13$ reverse primers. The diplomonad flagellate SSUrDNA sequence data were registered in the DNA Data Bank of Japan (DDBJ, https://www.ddbj.nig.ac.jp/index.html).

\section{Sequence alignment and phylogenetic analyses}

Partial SSUrDNA nucleotide sequences of 7 Spironucleus species, 3 Hexamita species, and 1 Octomitus species were obtained from the GenBank database: Spironucleus salmonis (accession no. DQ 394703), S. salmonicida (DQ181595), S. barkhanus (DQ186581), S. vortens (U93085), S. torosa (EF050055), S. meleagridis (EF050054), S. muris (EU043230), $H$. inflata (L07836), H. nelsoni (EF050053), Hexamita sp. (Z17224), and Octomitus intestinalis (DQ366277). A multiple sequence alignment analysis was performed, and a phylogenetic tree was constructed using ClustalW 2.1 software available from DDBJ.

\section{Results}

\section{Surface morphology}

Diplomonad flagellates heavily infested the surface of the intestinal epithelium in both the chum and masu salmon (Figs. 1A \& B). The bodies of the flagellates were unadorned, smooth and irregularly oval, with length of 7-9 $\mu \mathrm{m}$ and width of 3-5 $\mu \mathrm{m}$ (Figs. $1 \mathrm{C} \& \mathrm{D}$ ). There were no bacteria-like organisms on the body surface
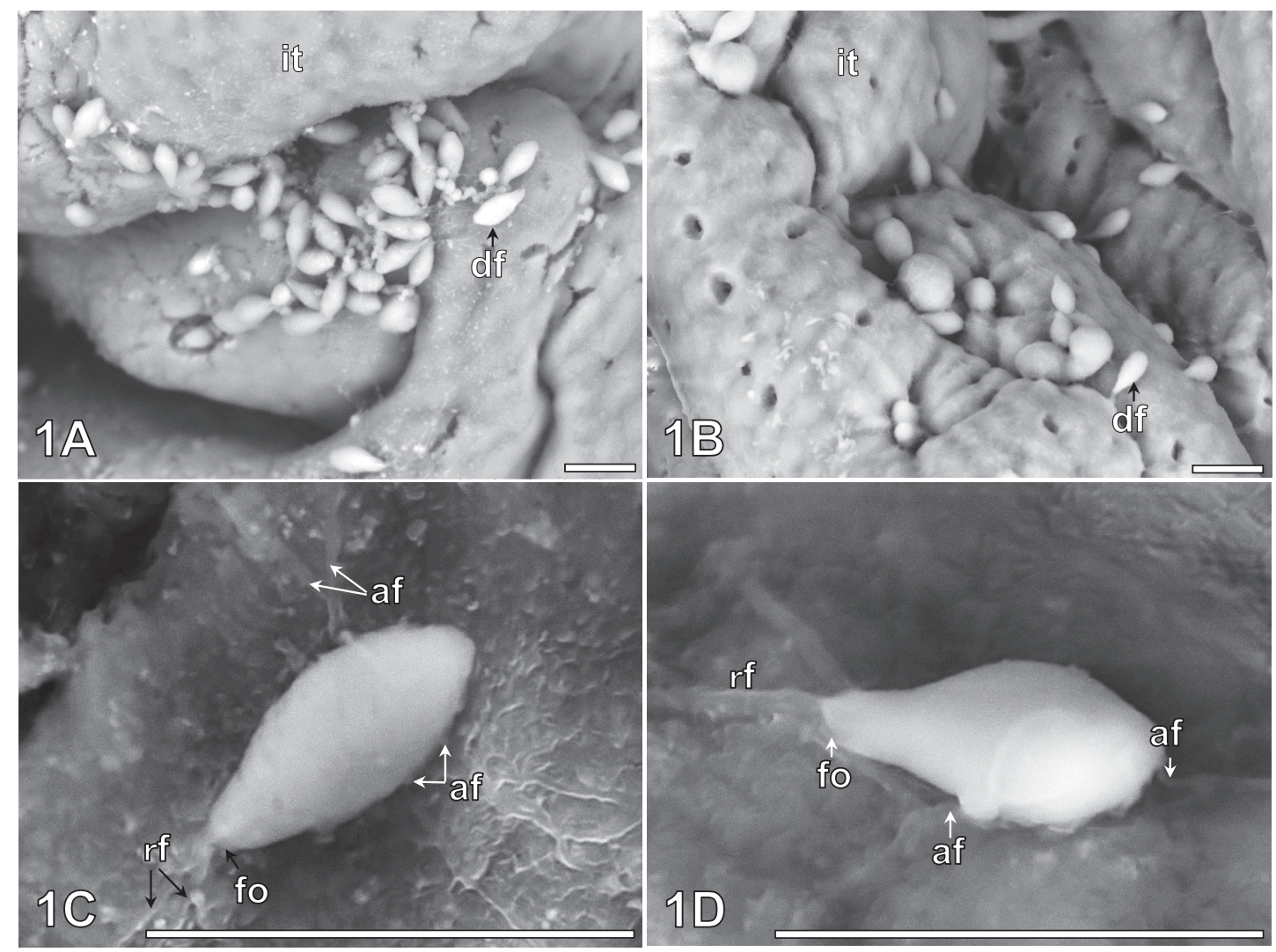

Fig. 1. Scanning electron micrographs of diplomonad flagellates infecting the intestine of juvenile chum and masu salmon. (1A) Diplomonad flagellates (df) infecting the intestinal epithelium (it) in chum salmon. (1B) Diplomonad flagellates (df) infecting the intestinal epithelium (it) in masu salmon. (1C) Lateral view of a diplomonad flagellate harvested from an infected chum salmon, showing the recurrent flagella (rf), anterior flagella (af), and recurrent flagellum opening (fo). (1D) Lateral view of a diplomonad flagellate harvested from an infected masu salmon, showing the recurrent flagella (rf), anterior flagella (af), and recurrent flagellum opening (fo). Scale bars show $10 \mu \mathrm{m}$. 
(Figs. 1C \& D). Plural anterior flagella and recurrent flagella extended from the anterior and posterior ends of the body, respectively (Figs. $1 C \& D$ ). There were no crescent-shaped ridges, which are an ultrastructural feature for species-level identification of $S$. salmonicida (Sterud et al., 1998), surrounding the recurrent flagellum openings at the posterior end (Figs. 1C \& D). The body of most of the flagellates was observed in contact with the intestinal epithelium of the fish (Figs. 1A-D). SEM was not able to detect more than two types of flagellates which had completely different surface morphology in each of chum and masu salmon.

\section{Cytoskeleton morphology}

The two recurrent flagella, running from the anterior to the posterior ends of the flagellate body (Figs. 2A \& B

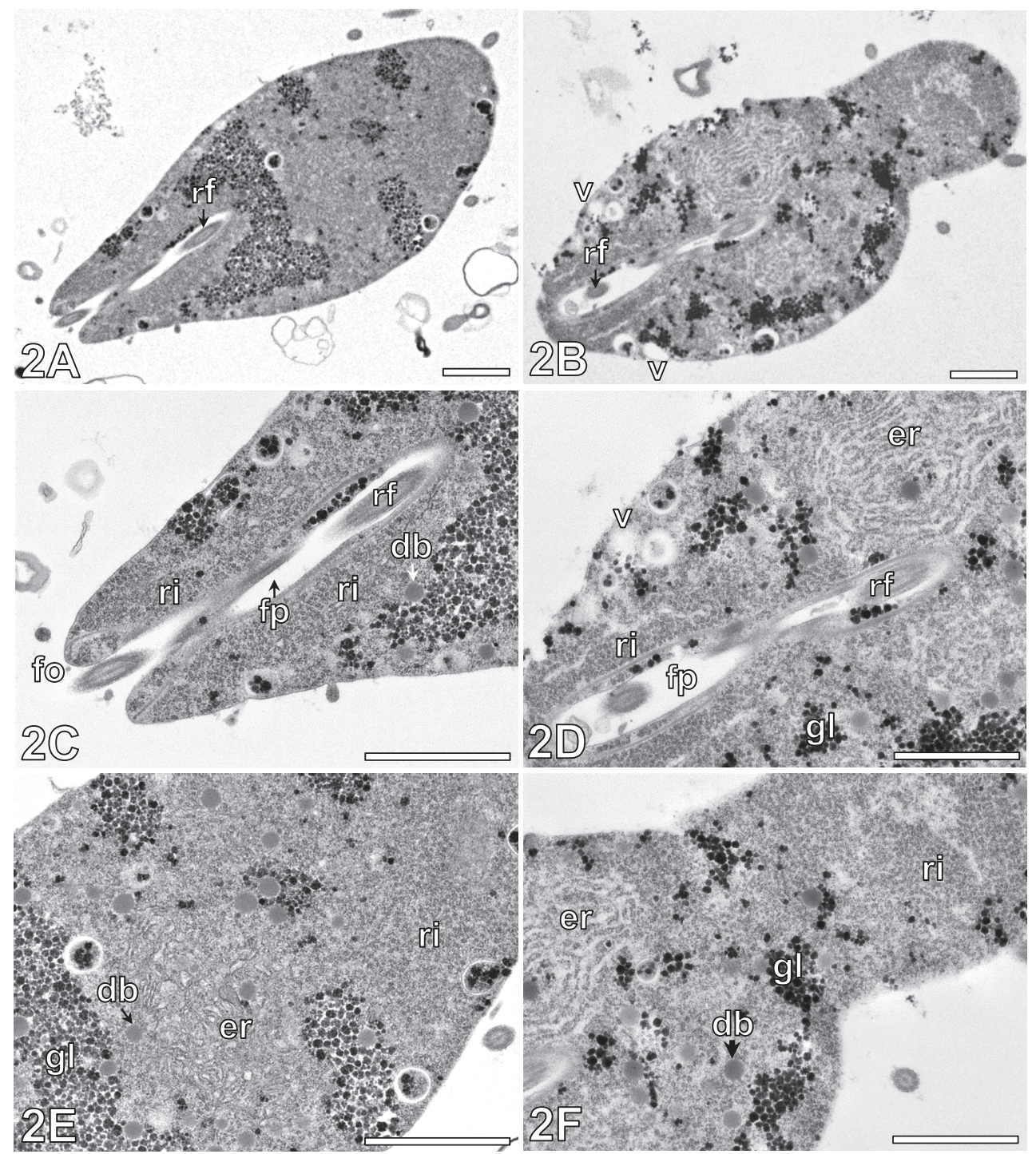

Fig. 2. Transmission electron micrographs of diplomonad flagellates harvested from the intestine of juvenile chum and masu salmon. (2A) Longitudinal section through a flagellate infecting a chum salmon, showing the recurrent flagellum (rf) running through the flagellate body. (2B) Longitudinal section through a flagellate infecting a masu salmon, showing the recurrent flagellum (rf) running through the flagellate body; note vacuoles $(\mathrm{v})$ at posterior portion of the flagellate. (2C) Posterior portion of the same flagellate depicted in Fig. 2A. The recurrent flagellum (rf) held in a flagellar pocket (fp) appears outside the body at the recurrent flagellum opening (fo). Numerous free ribosomes (ri) are sac-shaped around the recurrent flagellum (rf). Note the aggregation of glycogen granules $(\mathrm{gl})$ and electron dense body $(\mathrm{db})$ in the cytoplasm. (2D) Posterior portion of the flagellate shown in Fig. 2B. Note the recurrent flagellum (rf) from the flagellar pocket (fp), aggregation of glycogen granules (gl), developed rough endoplasmic reticulum (er), and the vesicle (v) in the cytoplasm. Numerous free ribosomes (ri) were sac-shaped around the recurrent flagellum (rf). (2E) Middle portion of the flagellate shown in Fig. 2A. Note the rough endoplasmic reticulum (er), numerous free ribosomes (ri), aggregation of glycogen granules ( $\mathrm{gl}$ ), and electron dense body $(\mathrm{db})$ in the cytoplasm. (2F) Middle portion of the flagellate shown in Fig. 2B. Note the rough endoplasmic reticulum (er), numerous free ribosomes (ri), aggregation of glycogen granules ( $\mathrm{gl}$ ), and electron-dense body (db) in the cytoplasm. Scale bars show $1 \mu \mathrm{m}$. 

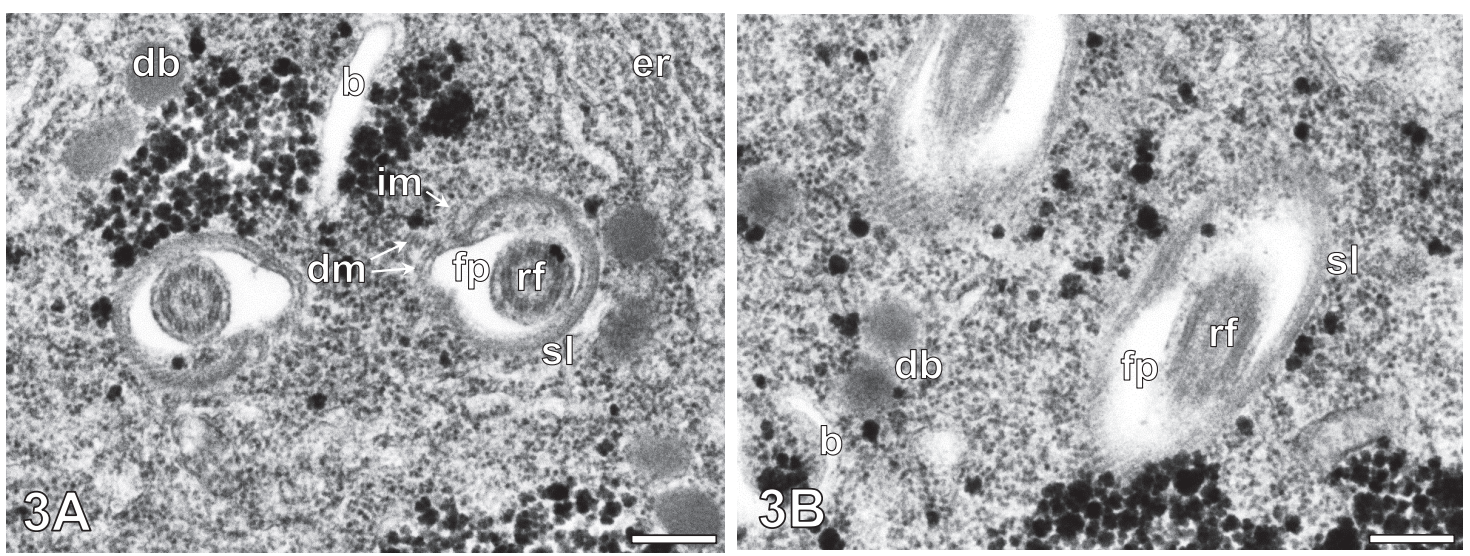

Fig. 3. Transmission electron micrographs showing cytoskeletal features of diplomonad flagellates from the intestine of juvenile chum and masu salmon. (3A) Transverse section showing radiated pattern of three microtubular bands at the opening of striated lamina (sl) surrounding the flagellar pocket (fp) and the recurrent flagellum (rf) through the middle of the flagellate body, harvested from a chum salmon. The three microtubular bands comprise an undulating row of direct microtubules (dm) lying between the tip of striated lamina (sl) and extending into the opening of the striated lamina (sl), a straight row of direct microtubules $(\mathrm{dm})$ radiating from the opening of striated lamina (sl), and a curved row of infra-nuclear microtubules (im) extending over the distended side of striated lamina (sl). Note the electron dense bodies (db), bowl-shaped membranous structure (b), and developed rough endoplasmic reticulum (er). (3B) Transverse section showing cytoskeletal features through the middle of the flagellate body, harvested from a masu salmon. Note the striated lamina (sl) surrounding the flagellar pocket (fp) and the recurrent flagellum (rf), electron dense bodies (db), and bowl-shaped membranous structure (b). Scale bars show $0.25 \mu \mathrm{m}$.

and $3 A$ \& $B)$, are held in flagellar pockets surrounded by striated lamina (Figs. $2 C \& D, 3 A \& B$ and $4 B$ \& $D$ ), and are distributed medially to two nuclei (Figs. $4 A$ \& B). The two nuclei are elongate and tapered, lying in the intracellular region on the anterior side (Figs. 4A \& C). The kinetosomes are located sub-apical to the nuclei on the anterior side (Figs. 4B \& D). The supra-nuclear microtubular bands closely follow the nuclear membranes ranging over the anterior of the nuclei (Fig. 4D). Infra-nuclear microtubular bands pass along the medial surface of the nuclei to the opening of the striated lamina surrounding the recurrent flagellum (Figs. $3 \mathrm{~A}$ and $4 \mathrm{~B}$ \& D). Direct microtubular bands radiate from the opening of the striated lamina (Figs. 3A \& 4D). Three microtubular bands (two direct bands and an infra-nuclear band) accompany the recurrent flagella and radiate from the opening of the striated lamina in the center portion of the flagellate body (Fig. 3A). Electron dense plaques exist beside the kinetosome as an anterior pattern (Fig. 4D) or between the recurrent flagella and striated lamina as a posterior pattern (Fig. 4B).

The crescent-shaped ridges on the body surface of the flagellates were not present around the recurrent flagellum openings in the posterior end of the flagellate body (TEM: Fig. 2C). A central axis formed by recurrent axonemes, microtubular bands, and endoplasmic reticulum was not observed; these ultrastructural features have been used for genus-level identification of Octomitus (Poynton and Sterud, 2002). Furthermore, there were no structures of microtubules supporting the surface ornamentation of the flagellate body, which are ultrastructural features for species identification of S. torosa and S. vortens (Poynton et al., 2004). Morphology of the intracellular cytoskeleton of the flagellates did not differ between the chum salmon and masu salmon hosts.

\section{Cytoplasm structure}

A lightly stained homogeneous region was located in the apical cytoplasm of the anterior end of the flagellate body (Fig. 4D). Electron dense bodies, numerous free ribosomes, a bowl-shaped membranous structure, aggregations of glycogen granules, developed rough endoplasmic reticulum, and vacuoles were distributed in the cytoplasm except for the lightly stained homogeneous region (Figs. 2B, C, E \& F, $3 A$ \& $B$ and $4 B \& D$ ). Electron dense plaques were distinguished from electron dense bodies by their precise position in the cytoplasm and their darkly staining structure (Poynton et al., 2004). Numerous free ribosomes were sac-shaped around the recurrent flagellum on the posterior side of the body (Figs. 2C \& D). Rough endoplasmic reticulum was often apparent around the recurrent flagellum in the center of the body (Figs. 2D \& 3A). The diplomonad flagellates came in contact with the host intestinal epithelium microvilli using their anterior flagellum and/or body surface (Figs. 4A-D), with a cytostome-like opening at the contact point with the intestinal microvilli (Fig. 4A \& B). In some situations there were transporting glycogen granules between the cytostome-like opening and the open vesicle including abundant glycogen granules (Fig. 4B). The cytoplasm morphology of the flagellates exhibited no variations between the chum and masu salmon hosts. More than two types of flagellates which 


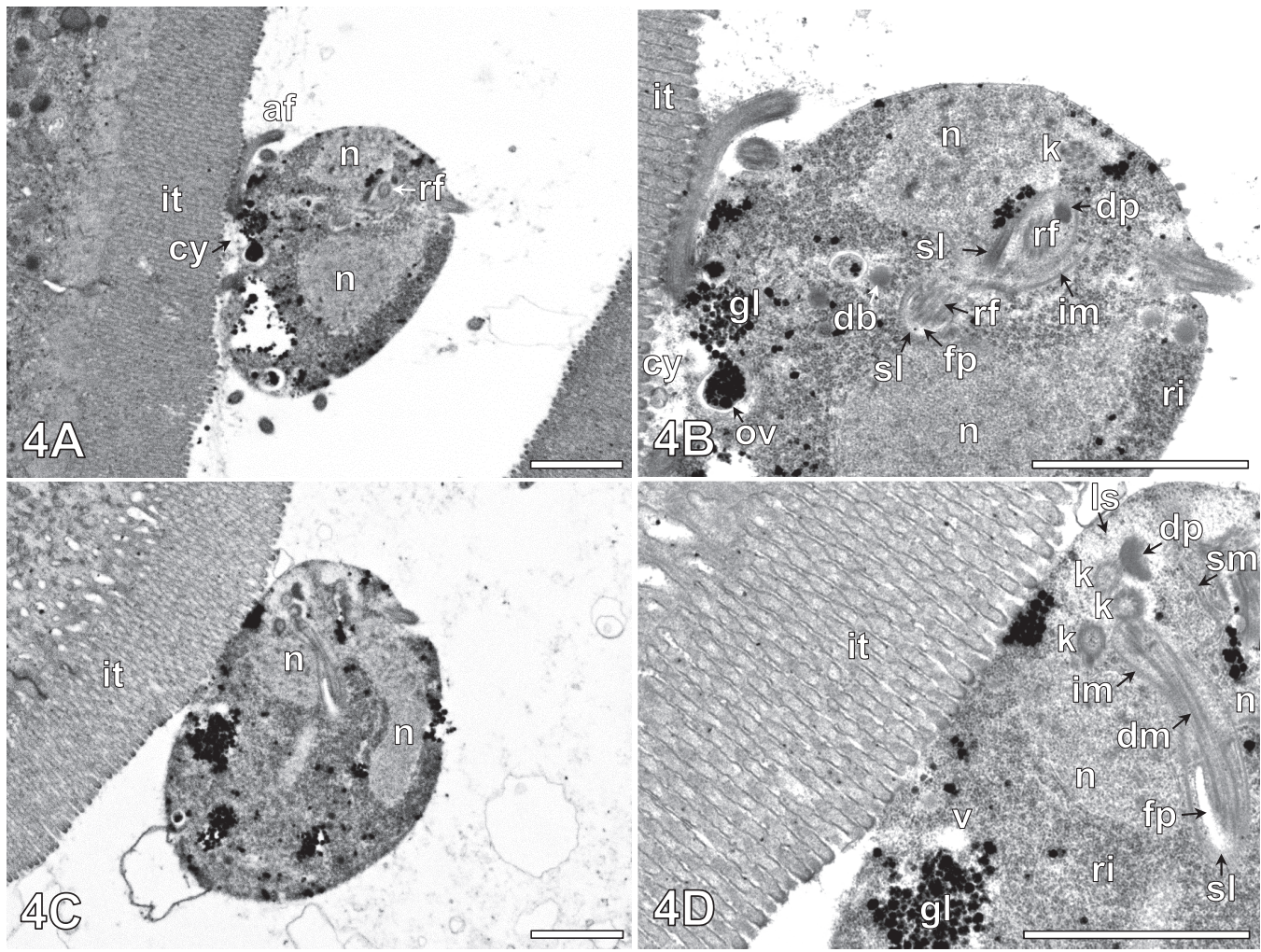

Fig. 4. Transmission electron micrographs showing diplomonad flagellates infecting juvenile chum and masu salmon, and their contact points with the intestinal epithelium microvilli of the host. (4A) Transverse section through the anterior portion of a flagellate from an infected chum salmon, and the intestinal epithelium microvilli (it) of the host. The flagellate comes in contact with the intestinal epithelium microvilli (it) using its anterior flagellum (af) and cytostome-like opening (cy). Note the pair of elongate and tapered nuclei (n) and the recurrent flagellum (rf). (4B) Enlarged picture of the flagellate shown in Fig. 4A, and its contact point with the intestinal epithelium microvilli (it) of the host. This TEM revealed abundant transporting glycogen granules (gl) between the cytostome-like opening (cy) and the open vesicle (ov) including glycogen granules ( $\mathrm{gl}$ ). The recurrent flagella (rf) distribute medially to the two nuclei (n). The flagellar pocket (fp) and recurrent flagellum (rf) are surrounded by striated lamina $(\mathrm{sl})$. Infra-nuclear microtubular band $(\mathrm{im})$ connects with the opening of striated lamina (sl). Electron dense plaque (dp) lies between the recurrent flagella and striated lamina. Note the electron dense body (db), developed free ribosomes (ri), and kinetosomes ( $k$ ) in the cytoplasm. The electron density of electron dense plaque (dp) is higher than that of electron dense body (db). (4C) Transverse section through the anterior portion of a flagellate infecting a masu salmon, and the intestinal epithelium microvilli (it) of the host. The flagellate comes in contact with the intestinal epithelium microvilli (it) using its body surface. Note the pair of elongate nuclei (n). (4D) Enlarged picture of the flagellate shown in Fig. 4C, showing its contact point with the intestinal epithelium microvilli (it) of the host. The infra-nuclear microtubular band (im) runs along the medial surface of nuclei $(\mathrm{n})$ to the opening of striated lamina (sl). Direct microtubular bands (dm) radiate from the opening of striated lamina $(\mathrm{sl})$. Electron-dense plaque $(\mathrm{dp})$ lies beside the kinetosome $(\mathrm{k})$ of an anterior flagellum. The supra-nuclear microtubular band (sm) extends over the anterior part of the nuclei $(\mathrm{n})$. Note the lightly stained homogeneous cytoplasm (Is), developed free ribosomes (ri), aggregation of glycogen granules (gl), flagellar pocket (fp), and vesicle (v) in the cytoplasm. Scale bars show $1 \mu \mathrm{m}$.

showed completely different TEM morphology were not detected in each of chum and masu salmon.

\section{Molecular phylogenetic analysis}

All isolated SSUrDNAs of the diplomonad flagellates had the same 1,031 bp sequence (GenBank accession number: LC496562), which did not differ between the chum and masu salmon. In the multiple sequence alignment analysis, the SSUrDNA was $99 \%$ homologous with that of $S$. salmonis $(1,029 \mathrm{bp} / 1,031 \mathrm{bp}) ; 79 \%$ with that of $S$. vortens (820 bp/1,031 bp); 75\% with that of $H$. nelsoni $(778 \mathrm{bp} / 1,031 \mathrm{bp}) ; 73 \%$ with that of $H$. inflata (760 bp/1,031 bp) and Hexamita sp. (755 bp/1,031 bp);
$71 \%$ with that of S. meleagridis (739 bp/1,031 bp); $\leq 70 \%$ with that of $S$. salmonicida (726 bp/1,031 bp), S. barkhanus (726 bp/1,031 bp), $S$. torosa (717 bp/1,031 bp), S. muris $(712 \mathrm{bp} / 1,031 \mathrm{bp})$ and Octomitus intestinalis (703 bp/1,031 bp). The diplomonad flagellates analyzed in this study were divided into three distinctly separate phylogenic tree branches (Fig. 5). The isolated diplomonad flagellate was grouped together with $S$. salmonis and $S$. vortens on one of the branches. This group branched off early into a single clade, following the divergence of $S$. vortens, and finally the isolated diplomonad flagellate and $S$. salmonis formed a single clade. 


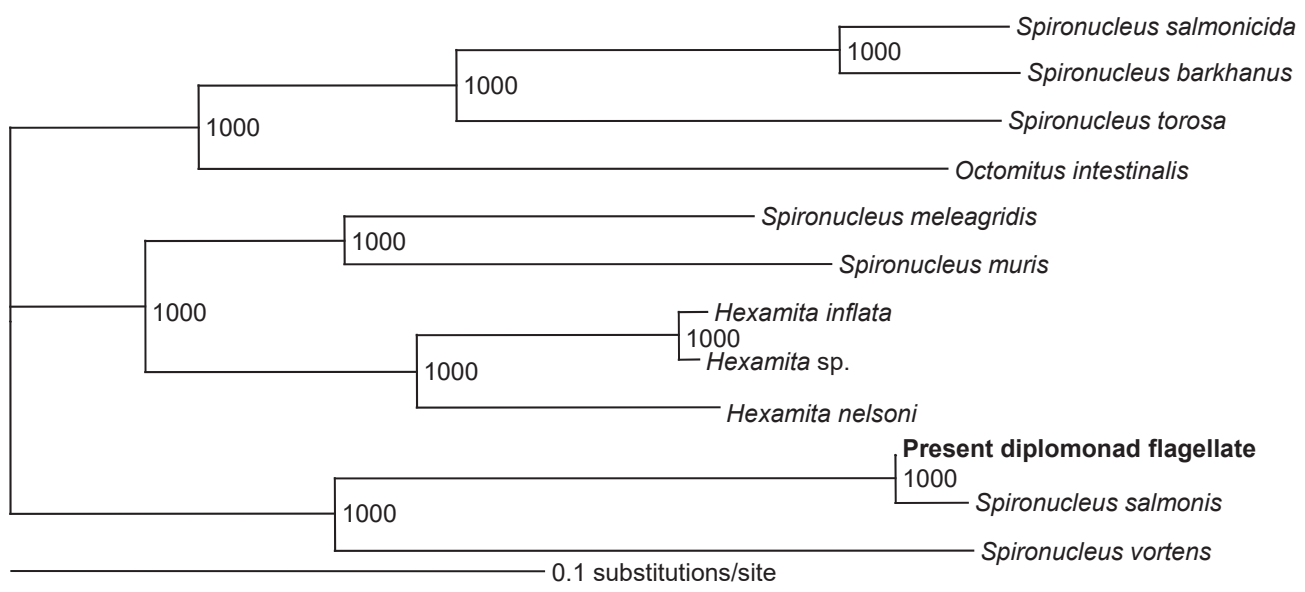

Fig. 5. Phylogenetic tree of the present diplomonad flagellate and 7 Spironucleus species, 3 Hexamita species, and 1 Octomitus species, inferred from nucleotide sequences of the small subunit ribosomal RNA gene. The phylogenetic tree was constructed by the neighbor-joining method, running 1,000 bootstrap replicates, using ClustalW 2.1 software available from the DNA Data Bank of Japan. Numerical values shown in the phylogenetic tree express bootstrap values of the branch.

\section{Discussion}

\section{Ultrastructural identification}

Table 1 compares the ultrastructural features used for genus- and species-level identification of S. salmonis, as applied in the present study and earlier studies (Poynton et al., 2004; Fard et al., 2007). The current results mostly satisfy the original requirements for distinguishing $S$. salmonis (Table 1). We propose that the diplomonad flagellate investigated belongs to genus Spironucleus based on the elongate and tapered nuclei and the sub-apical location of the kinetosomes in relation to the nuclei, which are features characterizing Spironucleus in relation to Spironucleus, Hexamita and Octomitus (Poynton and Sterud, 2002). Moreover, we conclude that the diplomonad flagellate could be ultrastructurally identified as $S$. salmonis because the presence of electron dense plaques at the posterior end, a posterior sac of abundant free ribosomes, an electron dense body, and bowl-shaped membranous structures, which are all characteristics distinguishing S. salmonis from S. salmonicida, S. torosa and S. vortens (Poynton et al., 2004). One disagreement between the present results and earlier studies is whether the flagellate comes in contact with the intestinal epithelium of the host (Table 1). In this study, TEM established that the organism clearly came in contact with the host's intestinal epithelium using its flagellum and/or body surface, which was first reported. Another notable finding concerns the abundant transporting glycogen granules between the cytostome-like opening and the open vesicle including glycogen granules; however, it is unclear whether this transportation in S. salmonis is performed in the extracellular or intracellular direction. The cytostome-like opening and the open vesicle differ in their ultrastructure from the discharged vesicle, which possibly functions in the excretion of digestion products in the extracellular direction in S. salmonis (as reported in the earlier studies by Poynton et al. 2004 and Fard et al. 2007), because the discharged vesicle has no glycogen granules. Although there have been few detailed studies on feeding and digestion in Spironucleus parasites, it is known that some diplomonad flagellates are phagotrophic, and endocytosis takes place at the cytostome located in the top of the flagellar pocket (Kulda and Nohynkova, 1978). This study found that the cytostome-like opening is quite different from the cytostome, because partial flagellar pockets were not found at the cytostome-like opening. Carbohydrate, which is generally stored as glycogen granules in the cytoplasm and used as the source of nutrition for flagellates (Millet et al., 2011), is possibly ingested from host intestinal epithelium microvilli covered with glycoprotein (Ashida, 2016). It is feasible that glycogen granules are taken into the flagellate body at the cytostome-like opening rather than being discharged from the flagellate body. Transportation of abundant glycogen granules at the cytostome-like opening possibly reflects the endocytosis of glycogen in S. salmonis. Specifically, these possibilities suggest that $S$. salmonis ingests nutrition from the host's intestinal epithelium at the cytostome-like opening, as well as at the cytostome.

\section{Molecular phylogenetic identification}

The SSUrDNA sequencing analysis demonstrated that all diplomonad flagellates examined in the present study genetically consisted of a single species because all isolated SSUrDNAs had the same nucleotide sequence. Furthermore, we conclude that the present flagellate can be molecularly identified as $S$. salmonis because the SSUrDNA of the flagellate had the highest homology (99\%) with S. salmonis among 11 examined 


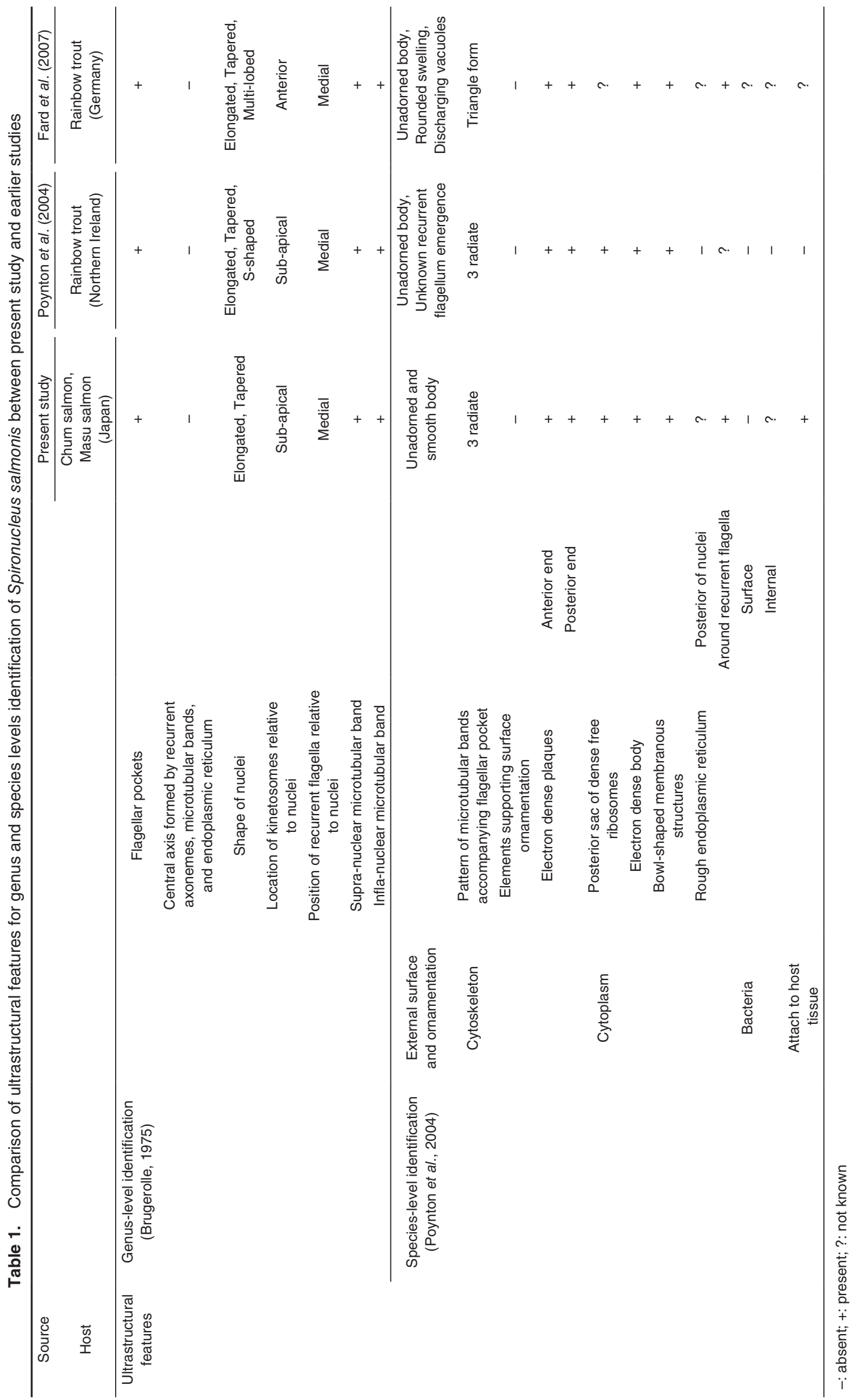


diplomonad flagellates. Also notable is that the $S$. salmonis in the present study grouped with $S$. vortens in the original branch. Our study was interested in comparisons of the morphology, hosts, and localities of $S$. salmonis and S. vortens. Spironucleus salmonis has an unadorned body and three radiating microtubular bands accompanying by a flagellar pocket, whereas $S$. vortens possesses a complicated adorned body and three staggered microtubular bands accompanying a flagellar pocket (Poynton et al., 2004; Fard et al., 2007; Williams et al., 2011). Spironucleus salmonis has been found in rainbow trout in the USA (Moore, 1922), Northern Ireland (Poynton et al., 2004), Germany (Fard et al., 2007) and Poland (Guz and Puk, 2015), as well as in brook trout Salvelinus fontinalis in the USA (Poynton and Morrison, 1990); S. vortens has been observed in freshwater angelfish Pterophyllum scalare in the USA (Poynton et al., 1995) and in red discus Symphysodon discus in the UK (Paull and Matthews, 2001). Spironucleus salmonicida has an unadorned body and three radiating microtubular bands accompanying a flagellar pocket, as in $S$. salmonis, and is known from salmonid species in Norway (Jorgensen and Sterud, 2006). Accordingly, S. salmonis is more similar to $S$. salmonicida as compared with $S$. vortens based on its morphology, host and locality, although $S$. salmonicida is distantly related to $S$. salmonis. This conflict may be a consequence of an artifact: the long-branch effects of sequences with increasing rates of evolution in early eukaryotic evolution (Stiller and Hall, 1999).

\section{Conclusions}

The present study used ultrastructure diagnosis and molecular phylogenetics to identify $S$. salmonis as the diplomonad flagellate infecting juveniles of chum and masu salmon in a single hatchery in Hokkaido. It is possible that $S$. salmonis is widely distributed in Hokkaido. The prevalence, pathogenicity, and infection source of $S$. salmonis in both wild and cultured salmonid fishes in Japan are yet to be determined, because methods to specifically detect and to quantify $S$. salmonis are not established in Japan. We encourage further studies on development of quantitative polymerase chain reaction system specific to $S$. salmonis and on its epizootiology as an important contribution to eradicating spironucleosis in salmonids in Japan.

\section{Acknowledgements}

The authors are grateful to Dr Masa-aki Fukuwaka, Eiji Suzuki, Yutaka Ishimura, and Shoji Yoshimitsu of the Hokkaido National Fisheries Research Institute, Japan Fisheries Research and Education Agency, and Dr Hiroki Asami of the Salmon and Freshwater Fisheries Research Institute, Hokkaido Research Organization, for their practical support and helpful discussions. This study was supported by JSPS KAKENHI Grant Number 18K05800. We thank Cynthia Kulongowski with the Edanz Group (www.edanzediting.com/ac) for editing a draft of this manuscript.

\section{References}

Ashida, H. (2016): Interaction between gut microbes and host through intestinal mucin. KASEAA, 12, 901-908. (In Japanese)

Awakura, T. and H. Matsumoto (1970): Studies on the Octomitus disease of yamabe and amago. Annual Report of the Hokkaido Fish Hatchery for Fiscal 1969, 125-126. (In Japanese)

Brugerolle, G. (1975): Contribution a l'étude cytologique et phylétique des diplozoaires (Zoomastigophorea, Diplozooa, Dangeard 1910). VI. Caractères généraux des diplozoaires. Protistologica, 11, 111-118.

Fard, M. R. S., A. Jorgensen, E. Sterud, W. Bleiss and S. L. Poynton (2007): Ultrastructure and molecular diagnosis of Spironucleus salmonis (Diplomonadida) from rainbow trout Oncorhynchus mykiss in Germany. Dis. Aquat. Org., 75, 37-50.

Guo, F. C. and P. T. Woo (2004): Detection and quantification of Spironucleus barkhanus in experimentally infected Atlantic salmon Salmo salar. Dis. Aquat. Org., 61, 175178.

Guz, L. and K. Puk (2015): First molecular identification of Spironucleus salmonis (Diplomonadida) from diseased rainbow trout Oncorhynchus mykiss in Poland. Med. Weter., 71, 497-499.

Jorgensen, A. and E. Sterud (2004): SSU rDNA gene sequence reveals two genotypes of Spironucleus barkhanus (Diplomonanida) from farmed and wild Arctic char Salvelinus alpinus. Dis. Aquat. Org., 62, 93-96.

Jorgensen, A. and E. Sterud (2006): The marine pathogenic genotype of Spironucleus barkhanus from farmed salmonids redescribed as Spironucleus salmonicida n. sp. J. Eukaryot. Microbiol., 53, 531-541.

Jorgensen, A. and E. Sterud (2007): Phylogeny of Spironucleus (Eopharyngia: Diplomonadida: Hexamitinae). Protist, 158, 247-254.

Kent, M. L., J. Ellis, J. W. Foumie, S. C. Dawe, J. W. Bagshawe and D. J. Whitaker (1992): Systematic hexamitid infection in seawater pen-reared chinook salmon. Dis. Aquat. Org., 14, 81-89.

Kulda, J. and E. Nohynkova (1978): Flagellates of human intestine and of intestines of other species, In "Parasitic protozoa" (ed. by J. P. Kreier). Academic Press, New York, pp. 2-138.

Millet, C. O., D. Lloyd, M. P. Coogan, J. Rumsey and J. Cable (2011): Carbohydrate and amino acid metabolism of Spironucleus vortens. Exp. Parasitol., 129, 17-26.

Mo, T. A., T. Poppe and L. Iversen (1990): Systematic hexamitosis in salt-water reared Atlantic salmon. Bull. Eur. Assoc. Fish Pathol., 10, 69-70.

Moore, E. (1922): Octomitus salmonis, a new species of intestinal parasite in trout. Trans. Am. Fish. Soc., 52, 74-97.

O'Brien, G. M., V. E. Ostland and H. Ferguson (1993): Spironucleus-associated necrotic enteritis in angelfish (Pterophyllum scalare). Can. Vet. J., 34, 301-303.

Paull, G. C. and R. A. Matthews (2001): Spironucleus vortens, a possible cause of hole-in-the-head disease in cichlids. Dis. Aquat. Org., 45, 197-202.

Poppe, T. and T. A. Mo (1993): Systematic, glanulomatous 
hexamitosis of farmed Atlantic salmon: interactions with wild fish. Fish. Res., 17, 147-152.

Poppe, T., T. A. Mo and L. Iversen (1992): Disseminated hexamitosis in sea-caged Atlantic salmon. Dis. Aquat. Org., 14, 91-97.

Poynton, S. L. and C. M. Morrison (1990): Morphology of diplomonad flagellates: Spironucleus torosa $\mathrm{n}$. sp. from Atlantic cod Gadus morhua L., and haddock Melanogrammus aeglefinus (L.) and Hexamita salmonis Moore from brook trout Salvelinus fontinalis (Mitchill). J. Protozool., 37, 369-383.

Poynton, S. L. and E. Sterud (2002): Guidelines for species descriptions of diplomonad flagellates from fish. J. Fish Dis., 25, 15-31.

Poynton, S. L., W. Fraser, R. Francis-Floyd, P. Rutledge, P. Reed and T. A. Nerad (1995): Spironucleus vortens n. sp. from the fresh-water Angelfish Pterophillum scalare: morphology and culture. J. Euk. Microbiol., 42, 731-742.

Poynton, S. L., M. R. S. Fard, J. Jenkins and H. W. Ferguson (2004): Ultrastructure of Spironucleus salmonis n. comb. (formerly Octomitus salmonis sensu Moore 1922, Davis 1926, and Hexamita salmonis sensu Ferguson 1979), with a guide to Spironucleus species. Dis. Aquat. Org., 60, $49-64$.

Sano, T. and M. Ushiyma (1970): Control measures and some biological observations of hexamitiasis in trout. Fish Pathol., 4, 125-129. (In Japanese)

Sterud, E. (1998): In vitro cultivation and temperature-dependent growth of two strains of Spironucleus barkhanus
(Diplomonadida: Hexamitidae) from Atlantic salmon Salmo salar and grayling Thymallus thymallus. Dis. Aquat. Org., 33, 54-61.

Sterud, E., T. A. Mo and T. Poppe (1998): Systematic spironucleosis in sea-farmed Atlantic salmon Salmo salar, caused by Spironucleus barkhanus transmitted from feral Arctic char Salvelinus alpinus? Dis. Aquat. Org., 33, 63-66.

Sterud, E., T. Poppe and G. Borno (2003): Intracellular infection with Spironucleus barkhanus (Diplomonadida: Hexamitidae) in farmed Arctic char Salvelinus alpinus. Dis. Aquat. Org., 56, 155-161.

Stiller, J. D. and B. D. Hall (1999): Long-branch attraction and the rDNA model of early eukaryotic evolution. Mol. Biol. Evol., 16, 1270-1279.

Tojo, J. L. and M. T. Santamaria (1998): Oral pharmacological treatments for parasitic diseases of rainbow trout Oncothynchus mykiss. I: Hexamita salmonis. Dis. Aquat. Org., 33, 51-56.

Urawa, S. (2011): Spironucleosis. In "New atlas of fish diseases", 2nd edition (ed. by K. Hatai and K. Ogawa). Midori Shobo, Tokyo, p. 35. (In Japanese)

Urawa, S. and T. Awakura (1994): Protozoan diseases of freshwater fishes in Hokkaido. Sci. Rep. Hokkaido Fish Hatchery, 48, 47-58.

Williams, C. F., D. Lloyd, S. L. Poynton, A. Jorgensen, C. O. M. Millet and J. Cable (2011): Spironucleus species: Economically-important fish pathogens and enigmatic singlecelled eukaryotes. J. Aquac. Res. Development, 1, $1-13$. 